\title{
Analyses of growing degree-days for agriculture in Atlantic Canada*
}

\author{
R. Gordon ${ }^{1}$, A. Bootsma ${ }^{2}$ \\ ${ }^{1}$ Plant Industry Branch, Nova Scotia Department of Agriculture and Marketing, Truro, Nova Scotia, Canada B2N 5E3 \\ ${ }^{2}$ Center for Land and Biological Resources Research, Research Branch, Agriculture Canada, Ottawa, Ontario, Canada K1A 0C6
}

\begin{abstract}
Growing degree-days (GDD) above base temperatures of 0,5 and $10^{\circ} \mathrm{C}$ provide a useful indicator for assessing seasonal crop development in the Atlantic region of Canada. GDD statistics can be useful for a variety of agricultural management decisions. This study presents seasonally accumulated average values of GDD above $5^{\circ} \mathrm{C}$ for all geographic regions of Atlantic Canada based on data from the 30 yr period 1956 to 1985 . Values ranged from a high exceeding 1800 GDD in several areas of the Maritimes to less than 800 for the northern tip of Newfoundland. 'Rules of thumb' procedures were established for estinating the probability that selected threshold GDD values were exceeded and for estimating accumulated GDD at selected probability levels for all 3 base temperatures. Average accumulated GDD for base temperatures of $0^{\circ} \mathrm{C}$ and $10^{\circ} \mathrm{C}$ were highly correlated with values for $5^{\circ} \mathrm{C}$ $\left(r^{2} \geq 0.97\right)$. Available GDD at probability levels of 5,10 and $25 \%$ were related to the mean accumulated GDD for all 3 base temperatures using linear regression relationships $\left(r^{2} \geq 0.97\right)$. Also, the probability of exceeding selected threshold values of accumulated GDD were related by second order regression functions $\left(r^{2} \geq 0.84\right)$ to the average GDD for each base temperature. By using these regression relationships, mean GDD $>5^{\circ} \mathrm{C}$ can be used to estimate GDD over a range of probabilities and probabilities for a range of $\mathrm{GDD}$ thresholds for 0,5 and $10^{\circ} \mathrm{C}$ base temperatures.
\end{abstract}

\section{INTRODUCTION}

Growing degree-days (GDD) are frequently used as a weather-based indicator for assessing crop development. For example, many farm weather radio broadcasts or climatological bulletins convey daily or weekly accumulations as insight into the current and ongoing status of the growing season. It is important, however, that users of GDD information understand the limitations inherent with the use of this, often misrepresented, concept.

The status of agricultural crops is determined separately by growth and development processes. In understanding the limitations of GDD's, these 2 processes must be differentiated. Crop growth refers to an increase in crop weight, height, volume or area over a certain time scale. Development refers to the timing or

\footnotetext{
- CLBRR Contribution No. 93-39
}

progress of the crop from one stage of maturity to the next. During this progress of the crop through its phases of development, considerable variations in growth may occur (Gardner et al. 1985).

In considering the potential growth as the dry matter accumulation of a crop, we can think of it as the product of the duration of growth (i.e. the inverse of the rate of development) and the rate of dry matter accumulation. In other words the potential yield is dependent on how quickly the crop moves through its stages of development and also the rate at which it accumulates dry matter. The rate of dry matter accumulation is related directly to a number of environmental factors including light, $\mathrm{CO}_{2}$, humidity, soil moisture and leaf water status over a fairly wide optimum temperature range. On the other hand, the duration of growth is nearly inversely proportional to temperature over a wide range of temperatures, provided the crop is grown in its region of adaptation and soil moisture and fertility are not limiting. This suggests that growth is 
the result of many environmental interactions when temperatures are within the optimum limits, while development is much more variable with changes in temperature. As a result, the use of the description 'growing' degree-days is in itself ambiguous in terms of its relationship with agricultural production. Gallagher (1979) indicated that a more suitable description would be thermal time, the 'thermal' indicating heat and the 'time' referring to the plants' view of time. Several other synonymous terms have been used to describe this relationship between temperature and crop development, including degree-days, heat sums or heat units (Nuttonson 1955). We believe that the term growing degree-days is a suitable reference for crop development provided the 'growing' is not assumed to imply growth.

As previously mentioned, temperature based GDD's provide a reliable indication of the development of many crops throughout the growing season (Gilmore \& Rogers 1958, Arnold 1959, Bauer et al. 1984). Based on simple and readily available weather station inputs, GDD's can assist with many farm management decisions. The ability to predict the current stage of the life cycle of a crop or pest can be helpful in the timing of herbicide application (Gage 1989), synchronizing the flowering or cross pollination of crops for hybrid seed production and establishing more precise irrigation scheduling techniques. Long-term average GDD's can be utilized for variety selection when used in conjunction with other climatic indices such as frost dates. GDD's can also be used to more effectively indicate suitable seeding dates as well as to assist in staggering planting dates in order to insure more orderly harvests (Edey 1977).

A great deal of attention has focussed on the determination of the low temperature at which development is zero (often referred to as the base temperature). This temperature above which development begins to occur varies between crops and with the stage of development of a single crop. Generally, however, base temperatures of $0^{\circ} \mathrm{C}$ (brussel sprouts, cabbage, parsley), $5^{\circ} \mathrm{C}$ (peas, forages) and $10^{\circ} \mathrm{C}$ (corn, soybeans, tomatoes) are considered appropriate for most agricultural crops (Edey 1977). Environment Canada (1982) published monthly and annual average GDD's for many long term climate stations in Atlantic Canada based on the 1951 to 1980 normal period, indicating the general acceptance of these base temperatures.

Most historical approaches have demonstrated GDD's as means or extremes, with few examining the accumulation of GDD's on a probabilistic basis. Edey (1977), however, demonstrated GDD accumulations above 5,10 and $13^{\circ} \mathrm{C}$ for various octile levels for $3 \mathrm{cli}$ mate stations in Atlantic Canada based on 1941 to 1970 normals. In designating the accumulation of GDD's from cumulative frequency analysis, the user has the ability to select a suitable probability level and base management decisions appropriately.

The objectives of this study are: (1) to present GDD information on a probability basis for all geographic regions of Atlantic Canada; (2) to establish rule of thumb approaches to readily estimate the probability of threshold GDD accumulations from known information for all geographic regions of Atlantic Canada; (3) to establish rule of thumb measures to estimate the accumulation of GDD's above a specific base temperature from the accumulation above another base temperature for all geographic regions of Atlantic Canada.

\section{METHODOLOGY}

The 115 climate stations employed in this study are listed in Table 1 and their locations are identified in Figs. 1 \& 2 . Stations with complete daily maximum and minimum air temperature measurements from 1956 through 1985 were used where possible $(n=57)$. This 30 yr period was considered of sufficient length to provide meaningful probability analyses while not too long to be significantly influenced by climatic change. A number of stations which had fewer than 30 yr data due to missing records during this period and/or different observational periods were also partially used in the analyses $(n=58)$. Some missing data were estimated objectively by a weighting algorithm based on actual measurements from nearby weather stations when possible to ensure completeness of record. The station data were available from a computer archive of daily climatological records maintained by Agriculture Canada, Center for Land and Biological Resources Research, in Ottawa. Daily climatological records were originally supplied to Agriculture Canada by the Atmospheric Environment Service, Downsview, Ontario.

Daily GDD's for each station for each year were calculated from April through November based on measured daily maximum $\left(T_{\max }\right)$ and minimum $\left(T_{\min }\right)$ air temperatures and a threshold or base temperature ( $\left.T_{\text {base }}\right)$ as follows:

$$
\begin{gathered}
G D D=\frac{T_{\max }+T_{\min }}{2}-T_{\text {base }} \\
\text { If } T_{\text {average }}=\frac{T_{\max }+\frac{T_{\min }}{2}<T_{\text {base }} \text { then } G D D=0}{}
\end{gathered}
$$

For this investigation, GDD's were calculated for base temperatures of 0,5 and $10^{\circ} \mathrm{C}$ due to the close relationship of these temperatures with the onset of crop development. The daily values from April through November were totalled to generate yearly amounts. 
The April through November time period was selected since it is an appropriate range for the Atlantic Canada growing season. Readers should be cautioned that inflated values may be generated when examining annual plant species which require suitable seeding and germination conditions early in the growing season.

The yearly calculations of GDD's for each station and base temperature were processed by a computer program to generate overall means and probability values. Each variable for each station was ranked from lowest to highest for all years of available data.
Probabilities were computed for each rank value by counting the number of years in which the values were (or were not) exceeded. Values were then computed for selected probability levels by linear interpolation. Data were also processed to examine for each station the probability of exceeding specific threshold values of GDD's at each location in a similar manner.

As this paper provides an attempt to assess the relations of GDD's with only minimal information, Figs. $3 \& 4$ have been prepared to indicate the average April through November GDD's above $5^{\circ} \mathrm{C}$ for Atlantic

Table 1 Atlantic Canada climate stations utilized for this study; each station number is followed by the station name (station numbers correspond to those in Figs. 1 \& 2). Asterisks ( $\left(^{\circ}\right.$ ) indicate there may be missing data for some years during the period of record

\begin{tabular}{|c|c|}
\hline \\
\hline \multicolumn{2}{|c|}{$\begin{array}{l}\text { New Brunswick } \\
18 \text { Acadia Forest Exp. St. }\end{array}$} \\
\hline 28 & Alma \\
\hline 9 & Aroostook \\
\hline 5 & Bathurst \\
\hline 10 & Bon Accord \\
\hline 23 & Buctouche \\
\hline 11 & Centreville \\
\hline 3 & Charlo A* \\
\hline 21 & Chatham A \\
\hline 20 & Doaktow \\
\hline 1 & Edmunston Fraser Co. \\
\hline 16 & Fredericton A \\
\hline 15 & Fredericton CDA \\
\hline 31 & Gagetown 2 \\
\hline 8 & Grand Falls Drummond \\
\hline 14 & Harvey Station \\
\hline 2 & Kedgwick• \\
\hline 7 & Little River Mine* \\
\hline 36 & Milltown \\
\hline 19 & Minto \\
\hline 24 & Moncton \\
\hline 25 & Moncton A \\
\hline 34 & Musquash ${ }^{\circ}$ \\
\hline 6 & Nepisiguit Fralls \\
\hline 17 & Oromocto \\
\hline 22 & Rexton \\
\hline 13 & Royal Road* \\
\hline 26 & Sackville \\
\hline 33 & Saint John • \\
\hline 32 & Saint John A \\
\hline & Searsville ${ }^{\bullet}$ \\
\hline & St. George \\
\hline 29 & Sussex \\
\hline & Upsalquitch Lake ${ }^{*}$ \\
\hline 12 & Woodstock: \\
\hline
\end{tabular}

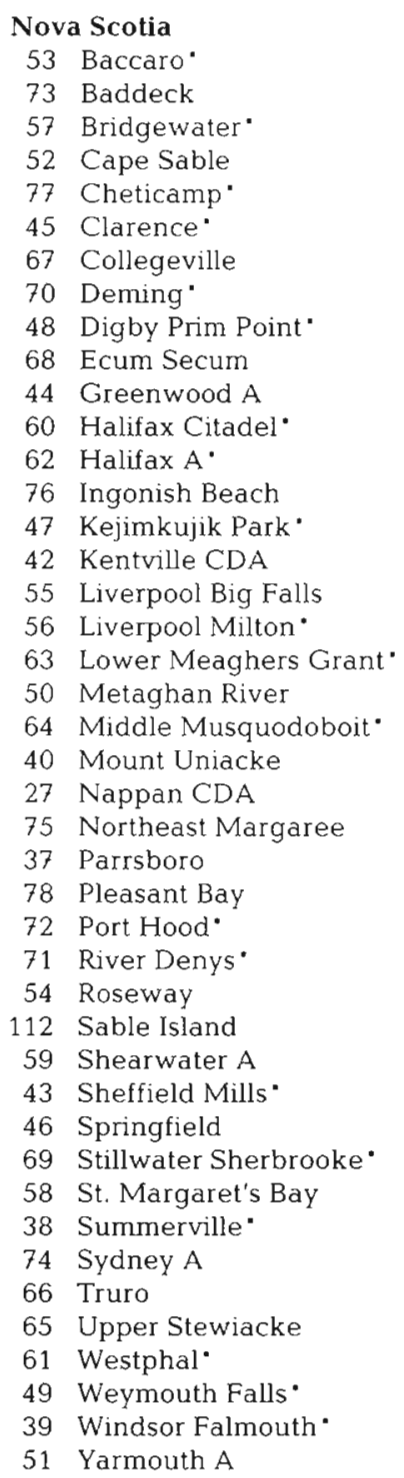

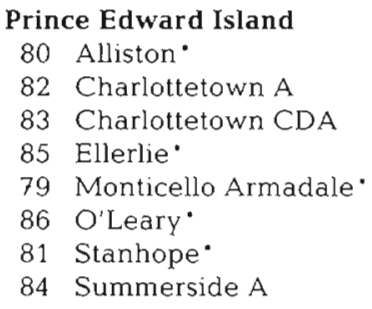




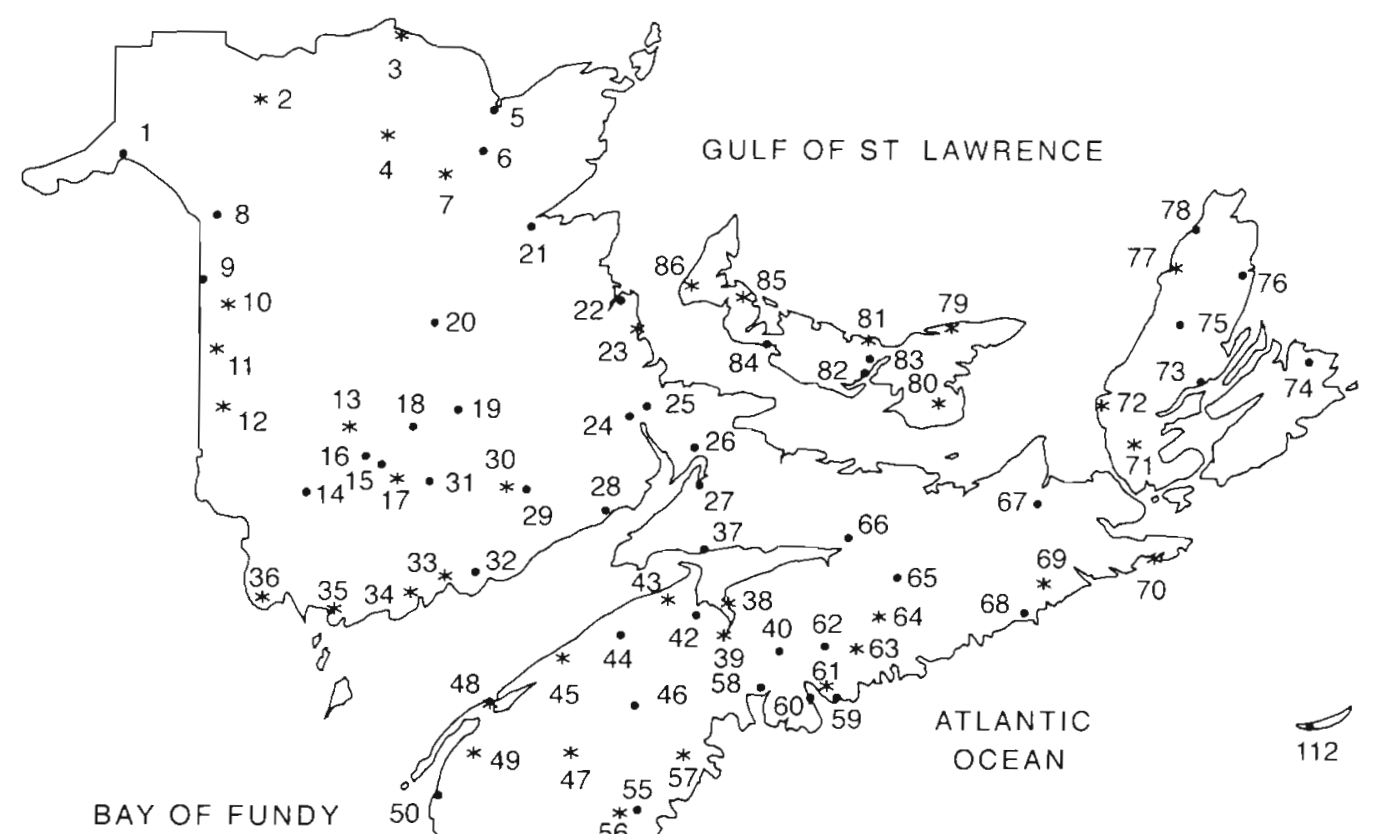

Fig. 1. Location of climate stations used in growing degree-day study for the Maritimes, Canada. (•) Complete 30 yr data, 1956 to 1985 ; (*) $20+$ yr data

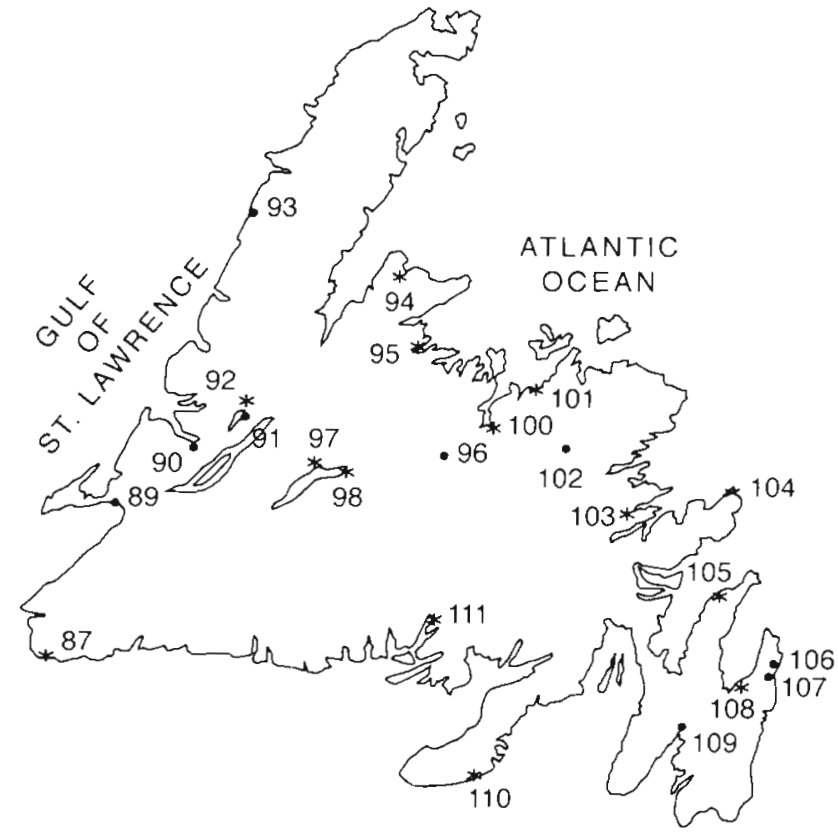

Fig. 2. Location of climate stations used in growing degreeday study for Newfoundland, Canada. ( $\bullet$ Complete 30 yr data, 1956 to $1985 ;(*) 20+$ yr data
Canada (based on $\mathrm{n}=115$ ). The isolines have been slightly modified from knowledge of topographic and coastal influences. These base maps will provide the minimal necessary information that will lead the user to a wealth of risk management information. By developing rule of thumb measures it is anticipated that knowledge of the mean GDD's above $5^{\circ} \mathrm{C}$ can be used to assess information at different probability levels and for different base temperatures.

Table 2. Regression equations for estimating April through November GDD $(Y)$ at selected probability levels from the average GDD value $(X)$ for base temperatures of $0^{\circ} \mathrm{C}, 5^{\circ} \mathrm{C}$ and $10^{\circ} \mathrm{C}$ in Atlantic Canada $(\mathrm{n}=57)$

\begin{tabular}{|crccr|}
\hline Base & $\begin{array}{c}\text { Prob. } \\
\text { level }\end{array}$ & $\begin{array}{c}\text { Regression } \\
\text { equation }\end{array}$ & $\mathrm{r}^{2}$ & $\mathrm{SE}$ \\
\hline $0^{\circ} \mathrm{C}$ & $5 \%$ & $Y=-305.243+1.023 X$ & 0.989 & 37.0 \\
& $10 \%$ & $Y=-214.349+1.008 X$ & 0.993 & 29.0 \\
& $25 \%$ & $Y=-136.492+1.014 X$ & 0.995 & 25.1 \\
& & & & \\
$5^{\circ} \mathrm{C}$ & $5 \%$ & $Y=-140.933+0.951 X$ & 0.983 & 26.0 \\
& $10 \%$ & $Y=-121.307+0.966 X$ & 0.977 & 21.9 \\
& $25 \%$ & $Y=-91.469+1.006 X$ & 0.991 & 19.2 \\
$10^{\circ} \mathrm{C}$ & $5 \%$ & $Y=-98.792+0.903 X$ & 0.981 & 12.6 \\
& $10 \%$ & $Y=-80.525+0.933 X$ & 0.986 & 11.0 \\
& $25 \%$ & $Y=-46.848+0.982 X$ & 0.993 & 8.3 \\
\hline
\end{tabular}


Fig. 3. Average growing degree-days above $5^{\circ} \mathrm{C}$ available from April through November in the Maritimes, Canada

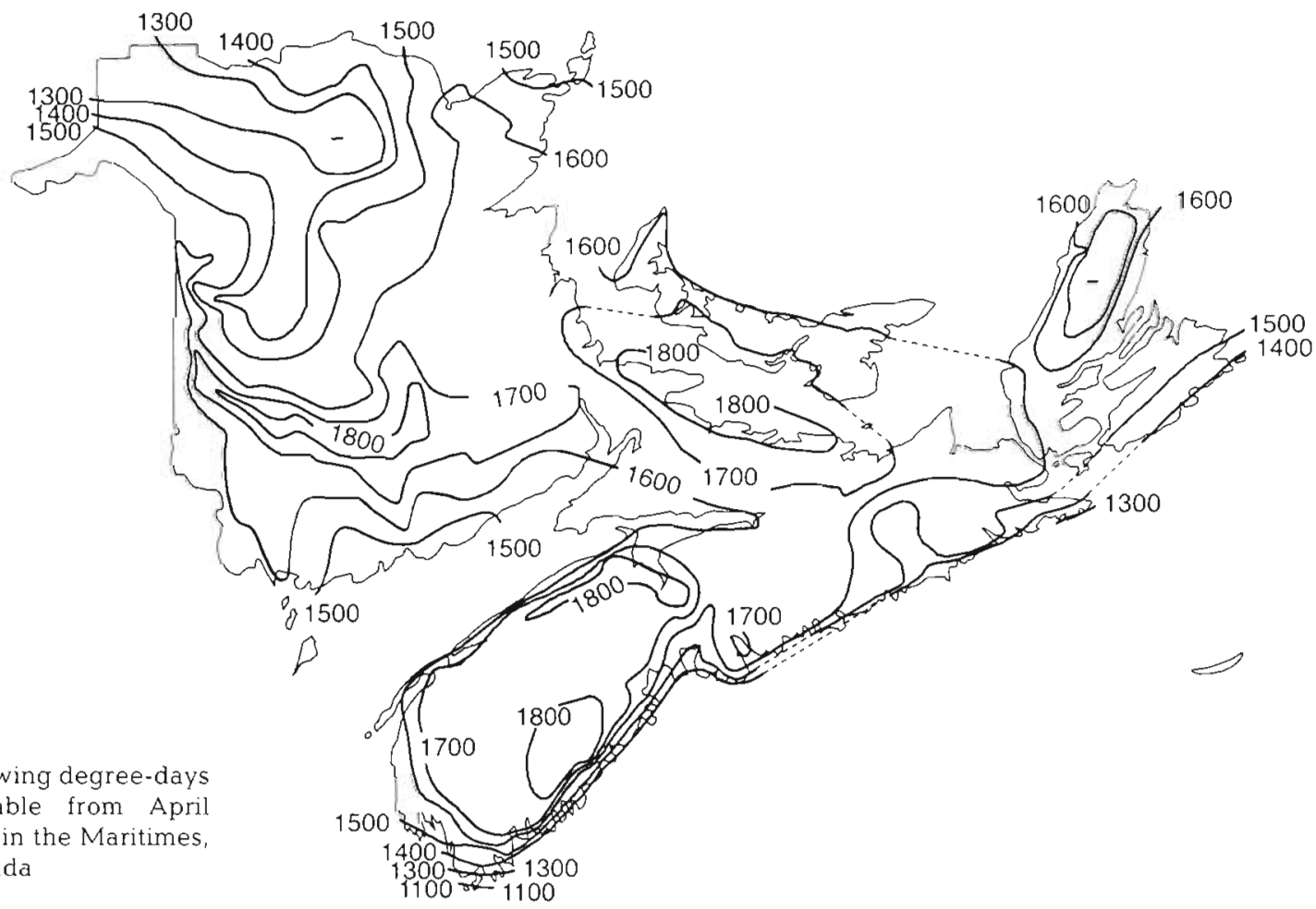

\section{RESULTS AND DISCUSSION}

Linear regression analysis (SAS Institute Inc. 1985) was used to develop equations which could estimate available GDD's above 0,5 and $10^{\circ} \mathrm{C}$ at probability levels of 5,10 and $25 \%$ from their respective mean values. The equations developed for this purpose are given in Table 2. Agreement between climate stations throughout the region was strong with all $r^{2}$ values exceeding 0.975 . A sample of the regressions is shown in Fig. 5 for the $0^{\circ} \mathrm{C}$ threshold at 2 probability levels ( 5 and $25 \%$ ). The strong correlation indicates that the long-term GDD's for all base temperatures have a normal distribution. Hence results for probability levels would be strongly correlated with the mean. All the resulting relationships between the mean GDD's and the GDD's at each probability level are given in Figs. 6 to 8 for base temperatures of 0,5 and $10^{\circ} \mathrm{C}$, respectively. These relationships allow the user to employ a rule of thumb approach to estimate GDD probabilities regardless of the geographic location, simply based on the mean GDD accumulation. For example, if the mean GDD accumulation for a location (in Atlantic

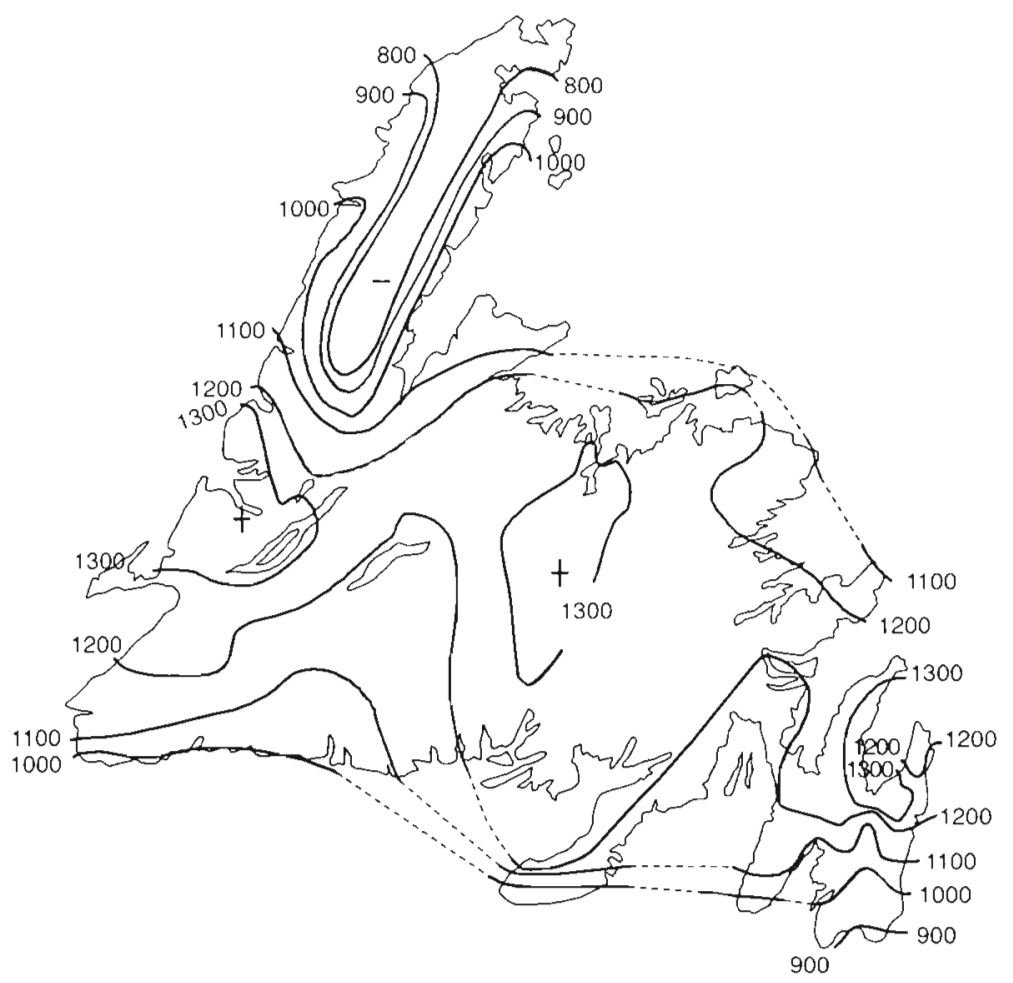

Fig. 4. Average growing degree-days above $5^{\circ} \mathrm{C}$ available from April through November in Newfoundland, Canada 


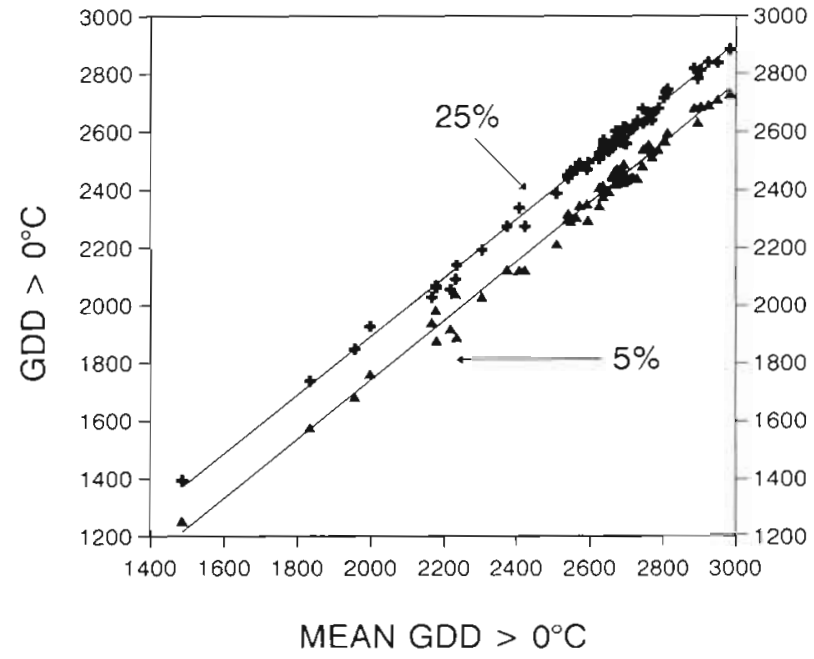

Fig. 5. Mean GDD's above $0^{\circ} \mathrm{C}$ plotted against GDD values above $0{ }^{\circ} \mathrm{C}$ at the $5 \%(\bullet)$ and $25 \%(+)$ probability levels. The best fit regression lines are those presented in Table 2

Canada) is 1700 GDD's above $5^{\circ} \mathrm{C}$ (Fig. 7) then the GDD accumulation at the $10 \%$ probability level (1 year in 10) should be approximately 1520 . In other words, 9 years out of 10 the GDD accumulation should equal or exceed 1520 .

Second order polynomial regression analysis based simply on knowledge of the mean GDD's was also performed to estimate the likelihood that GDD accumulation thresholds are exceeded. The results in Table 3 indicate the equations that can be used to estimate the

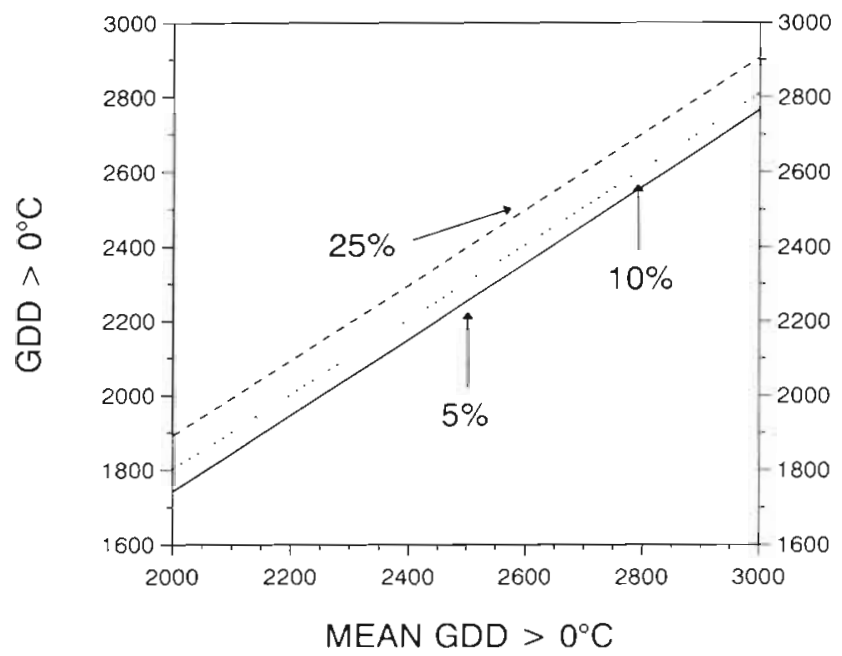

Fig. 6. Relationship between mean GDD's above $0^{\circ} \mathrm{C}$ and GDD values above $0^{\circ} \mathrm{C}$ at the 5,10 and $25 \%$ probability levels

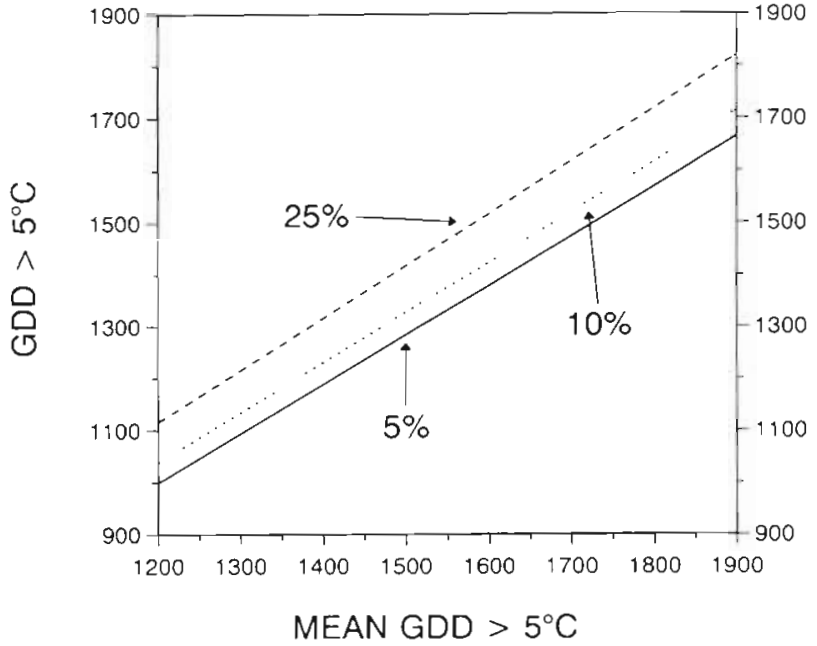

Fig. 7 Relationship between mean GDD's above $5^{\circ} \mathrm{C}$ and GDD values above $5{ }^{\circ} \mathrm{C}$ at the 5,10 and $25 \%$ probability levels

probability of exceeding threshold levels of GDD's from average GDD's for each base temperature. In almost all cases the $\mathrm{r}^{2}$ values exceeded 0.85 , which indicates that the average GDD's can be reliably used to estimate probabilities that given thresholds are exceeded. Figs. 9 to 11 further demonstrate this for base temperatures of 0,5 and $10^{\circ} \mathrm{C}$, respectively. For example, if a location has on average $2800 \mathrm{GDD}$ 's above $0^{\circ} \mathrm{C}$ (Fig. 9) there is a $100 \%$ probability that $2400 \mathrm{GDD}$ 's will be exceeded $(0 \%$ probability 2400 GDD's will not

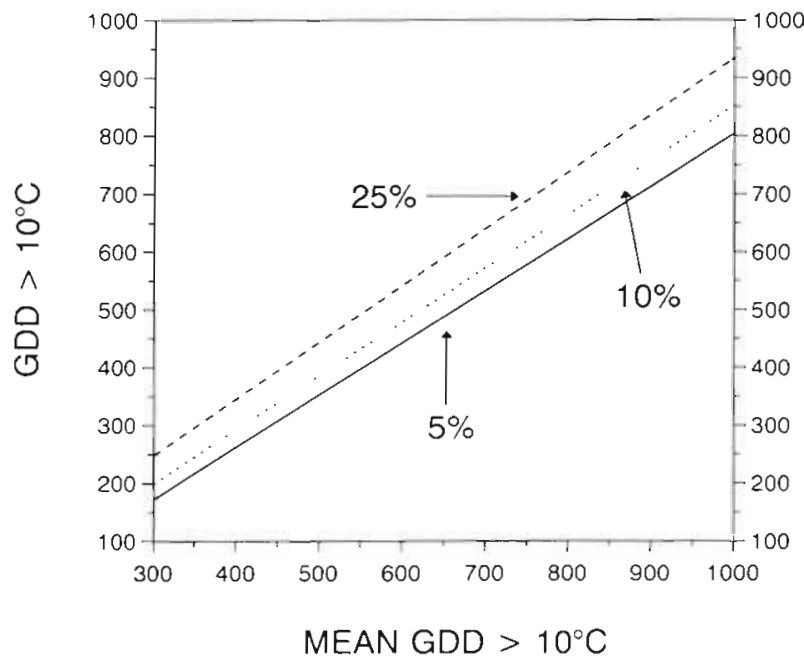

Fig. 8. Relationship between mean GDD's above $10^{\circ} \mathrm{C}$ and GDD values above $10^{\circ} \mathrm{C}$ at the 5,10 and $25 \%$ probability levels 
be exceeded) but only an $85 \%$ chance that 2600 GDD's will be exceeded $15 \%$ chance that 2600 GDD's will not be reached).

In Fig. 3 \& 4 the average April through November GDD's above $5^{\circ} \mathrm{C}$ for Atlantic Canada are shown and hence linear interpolation can be used to estimate the mean accumulation for any location in the region. Using the maps along with the regression equations, the GDD values available at selected probability levls (Table 2, Figs. 6 to 8 ) or the probability of various GDD thresholds being exceeded (Table 3, Figs. 9 to 11 ) can be assessed for any location in Atlantic Canada. For example, from Fig. 3 assume that a location with 1700 GDD's above $5{ }^{\circ} \mathrm{C}$ on average is identified. Since the average GDD total is known, estimates can be made at other probability levels. Fig. 7 shows that at $5 \%$ probability ( 1 year in 20) there are 1475 or fewer GDD's and at a $10 \%$ probability ( 1 year in 10 ) there are less than 1520 GDD's. Fig. 10 indicates that there is a $100 \%$ probability $(10$ years in 10$)$ that for any year a 1700 mean GDD location will equal or exceed 1200 GDD's. Furthermore a $70 \%$ probability $(7$ years in 10 ) exists that 1600 GDD's will be equalled or exceeded and a $20 \%$ probability (2 years in 10 ) that 1800 GDD's will be reached.

To apply the results to GDD's at other base levels regression equations were developed and are given in Table 4 to estimate the mean GDD's above 0 and $10^{\circ} \mathrm{C}$ from the mean $5^{\circ} \mathrm{C}$ GDD's. Strong agreement

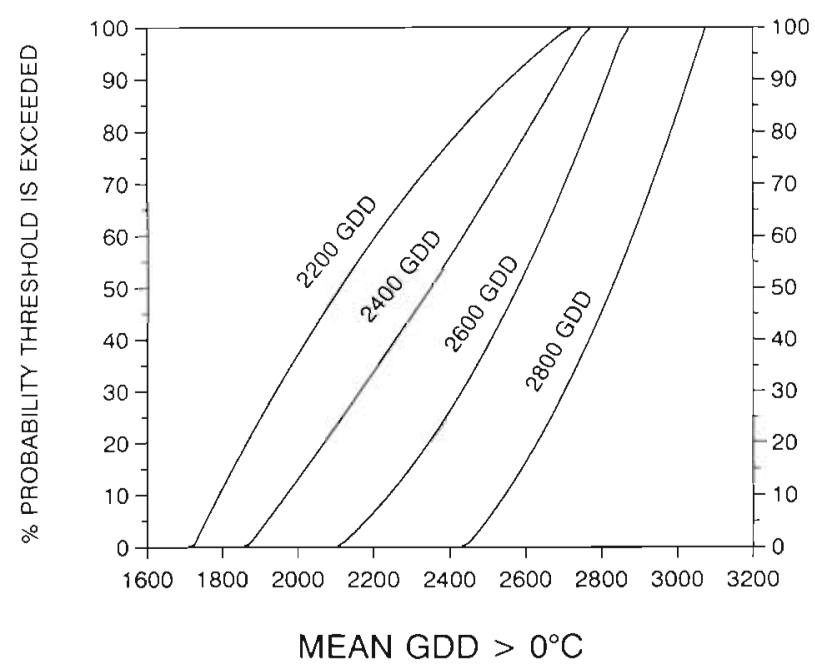

Fig. 9. Probability that GDD's above $0^{\circ} \mathrm{C}$ equal or exceed thresholds of $2200,2400,2600$ and 2800 in relation to the mean GDD above $0^{\circ} \mathrm{C}$
Table 3. Regression equations for estimating the probability $(Y)$ of exceeding selected threshold levels of GDD's in Atlantic Canada for April through November from the average GDD value $(X)$ for base temperatures of $0^{\circ} \mathrm{C}, 5^{\circ} \mathrm{C}$ and $10^{\circ} \mathrm{C}(\mathrm{n}=57)$

\begin{tabular}{|c|c|c|c|}
\hline Base & Threshold & Regression equation & $r^{2}$ \\
\hline \multirow[t]{4}{*}{$0^{\circ} \mathrm{C}$} & 2200 & $Y=-387.20+0.3037 X-0.0000458 X^{2}$ & 0.868 \\
\hline & 2400 & $Y=-114.84+0.0279 X+0.0000180 X^{2}$ & 0.857 \\
\hline & 2600 & $Y=+278.86-0.3266 X+0.0000922 X^{2}$ & 0.942 \\
\hline & 2800 & $Y=+505.31-0.4970 X+0.0001188 X^{2}$ & 0.843 \\
\hline \multirow[t]{4}{*}{$5^{\circ} \mathrm{C}$} & 1200 & $Y=-262.58+0.3905 X-0.0001034 X^{2}$ & 0.899 \\
\hline & 1400 & $Y=-130.38+0.1286 X+0.0000036 X^{2}$ & 0.874 \\
\hline & 1600 & $Y=+151.72-0.3192 X+0.0001600 X^{2}$ & 0.939 \\
\hline & 1800 & $Y=+214.33-0.3714 X+0.0001520 X^{2}$ & 0.843 \\
\hline \multirow[t]{3}{*}{$10^{\circ} \mathrm{C}$} & 400 & $Y=-110.97+0.5410 X-0.0003400 X^{2}$ & 0.949 \\
\hline & 600 & $Y=-100.50+0.3364 X-0.0001212 X^{2}$ & 0.901 \\
\hline & 800 & $Y=+58.02-0.3124 X+0.0003740 X^{2}$ & 0.933 \\
\hline
\end{tabular}

between the mean GDD's above both 0 and $10^{\circ} \mathrm{C}$ appears to exist with the mean $5^{\circ} \mathrm{C}$ GDD as evident by both $\mathrm{r}^{2}$ values exceeding 0.96 . As a result the relationships given in Table 4 and in Fig. 12 can be used to estimate the April through November accumulation above $0^{\circ} \mathrm{C}$ and $10^{\circ} \mathrm{C}$ from the heat unit accumulation above $5^{\circ} \mathrm{C}$. For example, if a location measured 1000 GDD's above $5^{\circ} \mathrm{C}$, then approximately 390 GDD's above $10^{\circ} \mathrm{C}$ could be expected. The same procedure could be performed to estimate the April through November accumulations above $0^{\circ} \mathrm{C}$. This allows the user to estimate the probability of exceeding specific

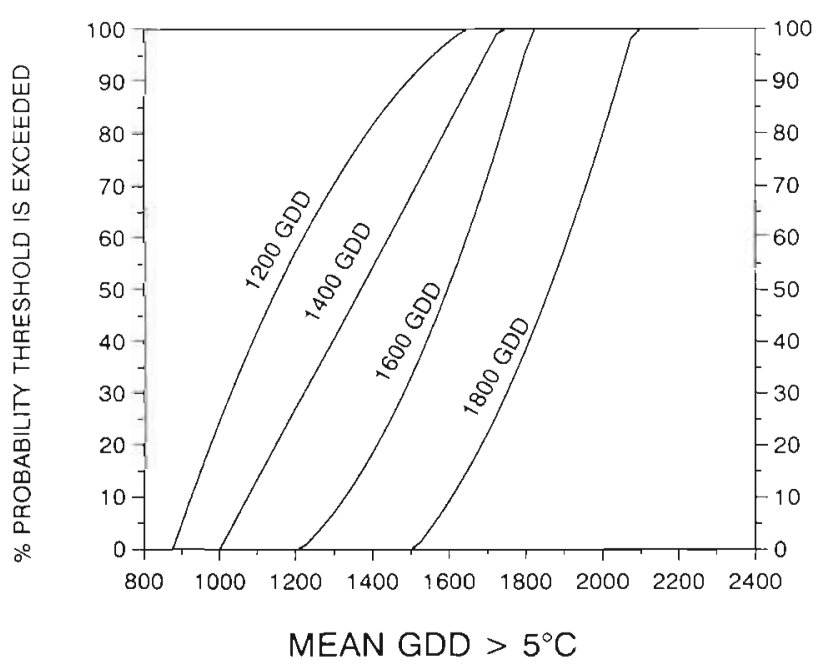

Fig. 10. Probability that GDD's above $5^{\circ} \mathrm{C}$ equal or exceed thresholds of $1200,1400,1600$ and 1800 in relation to the mean GDD above $5^{\circ} \mathrm{C}$ 


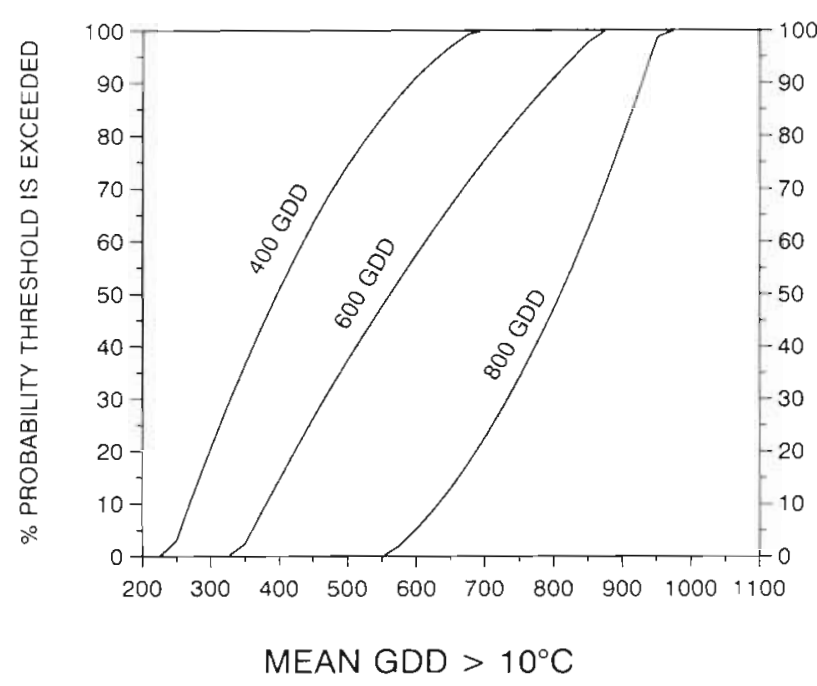

Fig. 11 Probability that GDD's above $10^{\circ} \mathrm{C}$ equal or exceed thresholds of 400,600 and 800 in relation to the mean GDD above $10^{\circ} \mathrm{C}$

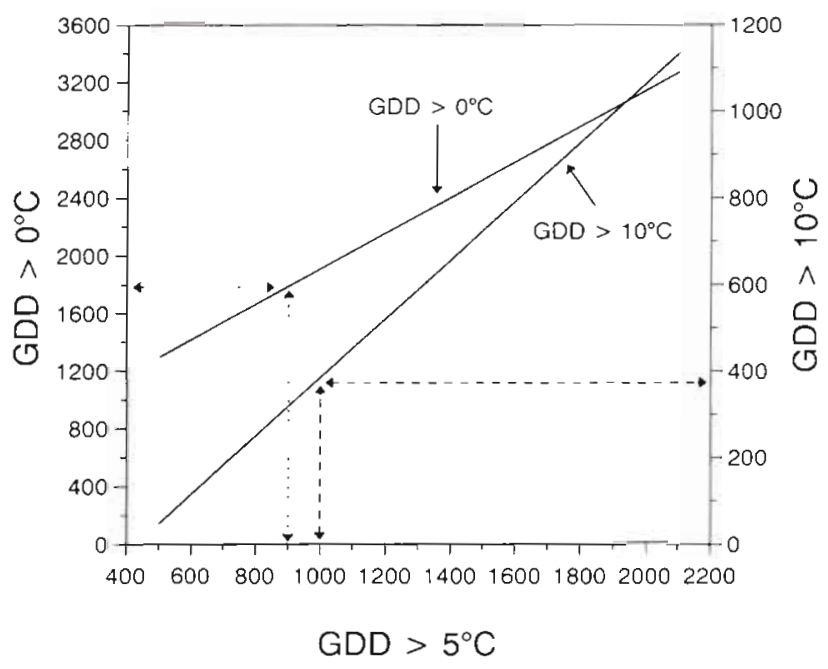

Fig. 12. Relationship between mean GDD's above $5^{\circ} \mathrm{C}$ and mean GDD's above $0^{\circ} \mathrm{C}$ and $10^{\circ} \mathrm{C}$

thresholds of GDD's (Table 3, Figs. $9 \& 11$ ) or determine the accumulations at various probability levels for 0,5 or $10^{\circ} \mathrm{C}$ base temperatures (Tabe 2, Figs. 6 to 8 ) by having knowledge of the mean GDD's for each base temperature.

Using the procedures developed here, a variety of statistics on GDD can be generated for any location in the Atlantic region. Although these statistical relationships cannot be applied to an extended area, it is

Editor: V. Meentemeyer
Table 4. Regression equations for estimating the Atlantic Canada April through November GDD's for base temperatures of $0^{\circ} \mathrm{C}\left(Y_{0}\right)$ and $10^{\circ} \mathrm{C}\left(Y_{10}\right)$ from April through November GDD's for base temperature of $5^{\circ} \mathrm{C}\left(Y_{5}\right)(n=117)$

\begin{tabular}{|lcc|}
\hline Regression equation & $\mathrm{r}^{2}$ & $\mathrm{SE}$ \\
\hline$Y_{0}=683.19+1.231689 Y_{5}$ & 0.9801 & 50.68 \\
$Y_{10}=-291.93+0.674733 Y_{5}$ & 0.9605 & 39.54 \\
\hline
\end{tabular}

hoped that this information will serve a useful standard in supplying GDD information for agricultural planning decisions.

Acknowledgements. The assistance of the Data Processing group of Agriculture Canada CLBRR in computer processing of the climatic data is gratefully acknowledged. Thanks also to the Cartographic Services of the Plant Industry Branch of the Nova Scotia Department of Agriculture and Marketing for map generation. Numerous weather observers have contributed to this study by faithfully recording weather observations on a daily basis for many years.

\section{LITERATURE CITED}

Arnold, C. Y (1959). The determination of the significance of the base temperature in a linear heat unit system. Proc. Am. Soc. Hortic. Sci. 74: 430-455

Bauer, A., Fanning, C., Enz, J. W., Eberlein, C. V. (1984). Use of growing-degree days to determine spring wheat growth stages. North Dakota State Univ. Agric. Ext. Bull. EB-37, Fargo

Edey, S. N. (1977). Growing degree-days and crop production in Canada. Agriculture Canada Publication 1635, Ottawa

Environment Canada (1982). Canadian climate normals, Vol. 4, Degree-days 1951-1980. Canadian Climate Program, Downsview, Ontario

Gage, S. H. (1989). Predicting pest occurrence and impact in a dynamic environment. In: Weiss, A. (ed.) Proceedings of Conference on Climate and Agriculture Systems Approaches to Decision Making, Mar 5-7, 1989, Charleston, SC, p. 118-131

Gallagher, J. N. (1979). Field studies of cereal leaf growth. J. exp. Bot. 30(117): 625-636

Gardner, F. P., Pearce, R. B., Mitchell, R. L. (1985). Physiology of crop plants. Iowa University State Press, Ames

Gilmore, E. C. Jr, Rogers, J. S. (1958). Heat units as a method of measuring maturity in corn. Agron. J. 50: 611-615

Nuttonson, M. Y (1955). Wheat-climate relationships and the use of phenology in ascertaining the thermal and photothermal requirements of wheat. Am. Inst. Crop Ecol., Washington, DC

SAS Institute Inc. (1985). SAS user's guide: Statistics, Version 5 edn. SAS Institute, Inc., Cary, NC

Manuscript first received: May 1, 1993

Revised version accepted: July 30, 1993 